\title{
High Speed Rail, a new mode of suburban metropolitan transport
}

\author{
M. Garmendia, J. M. Ureña, A. Rivas, J. M. Coronado, \\ J. M. Menéndez, I. Gallego \& V. Romero \\ University of Castilla La Mancha, Spain
}

\begin{abstract}
High Speed Rail (HSR) was conceived as an alternative to air transport to interconnect big cities and metropolises from 400 to $600 \mathrm{~km}$ distances. Recently these HSR lines are starting to have stations in traditional cities or new urban developments within the limits of each metropolis (between 20 and $100 \mathrm{~km}$ from the centre). The existence of these HSR stations in the periphery of metropolises is opening up two new metropolitan transportation behaviour possibilities. Firstly, the HSR used between central and peripheral metropolitan stations as a special new type of suburban metropolitan transport and secondly, peripheral HSR stations used to travel to/from other faraway places instead of using the central HSR stations.

This paper describes this new type of HSR cities, lines, stations and services, and points out several cases in Spain, France, Sweden and Great Britain where this is taking place. Data from two survey campaigns just implemented on the HSR passengers between Madrid and Toledo, and Madrid and Guadalajara is used to describe and analyse their profile. The paper points out the possibilities of this new type of HSR to help the generation of metropolitan sub-centres and to extend the metropolitan influence further away, analyses the HSR travelling patterns and allows indications of the type of processes that are taking place.
\end{abstract}

Keywords: metropolitan areas, small cities, high-speed rail.

\section{Introduction}

Several High Speed Rail (HSR) lines have been opened in Europe since the 1980s and 1990s. At the start, they were thought to be like a substitute of the air transport between metropolitan areas, over distances from 400 to $600 \mathrm{~km}$. 
Progressively, intermediate stations would appear in the aforementioned lines for a variety of reasons, from the railway's need to for security stops, the socioeconomic or political arguments of not leaving some cities or regions without a station, or of opportunity due to the facility of accomplishing a station in places where a HSR line was going to pass anyway.

The effects of the HSR in big cities, such as Madrid, Seville, Paris, Lyon, etc., are hardly distinguishable from other improvements to transportation, as well as from other urban or economic strategies. Besides, the aforementioned cities already had high-quality and high-speed communications before the HSR (Plassard [1]). On the other hand, understanding strategies and the effects of the HSR in small and isolated cities (i.e. Ciudad Real) has been relatively simple, granted that previously the dynamics of the aforementioned cities were small. However, HSR stations appearing in cities, each time nearer to big metropolitan areas, puts forward new issues relative to the use of this infrastructure as metropolitan transportation.

This communication puts forward the case that cities of small size are already totally or partially integrated in the metropolitan processes. In these cases, isolating the consequences from the HSR of other aspects derived of the very metropolitan processes does not prove to be possible; they should rather be considered as part of the said processes. In short, it comes into question that these HSR stations can have, at least, two different roles, in terms of their position in and their connection with the metropolitan area. Firstly, being useful like other metropolitan means of transportation for those cities or suburban outermost areas of the metropolitan centre, with special natures (greater velocity and a fewer number of stops than the other metropolitan railways); secondly, working like a second HSR station of the metropolitan area, one with better access to the peripheral inhabitants or workers of the metropolitan area.

\section{HSR and metropolitan integration}

Small cities that are less than $100 \mathrm{~km}$ of a metropolitan area are already considerably integrated in the latter. Cities, such as Toledo and Segovia, already presented significant travel-to-work displacements between these cities and Madrid in the year 2001, before the HSR came into service. Around 3\% and $3.5 \%$ respectively of the occupied population in the aforementioned cities worked in the municipality of Madrid and $4.25 \%$ and $5 \%$ respectively when considering the region of Madrid. These percentages are even greater in the case of Guadalajara $(8 \%, 2 \%$ and $14 \%, 8 \%)$, which is located $58 \mathrm{~km}$ from the centre of Madrid.

In these cases, the metropolitan integration of these small cities might increase by means of a new transport infrastructure which, in general, will not provide connection with other metropolitan intermediate places, but only with the very centre of the metropolitan area (Fig. 1).

Ureña et al. [2] suggested that the most specific opportunity of the HSR for these small cities would not be the reinforcement of their metropolitan integration, because they already have at their disposal many other metropolitan 
transport infrastructures (highways, suburban railway, bus services, etc.), but the fact that the same HSR service that connects the centre of the metropolitan area with other faraway places would be available for the metropolitan periphery in these cities. HSR stations at the metropolitan outskirts or periphery can be understood as an urban process similar to the gathering of tertiary activities around metropolitan airports.
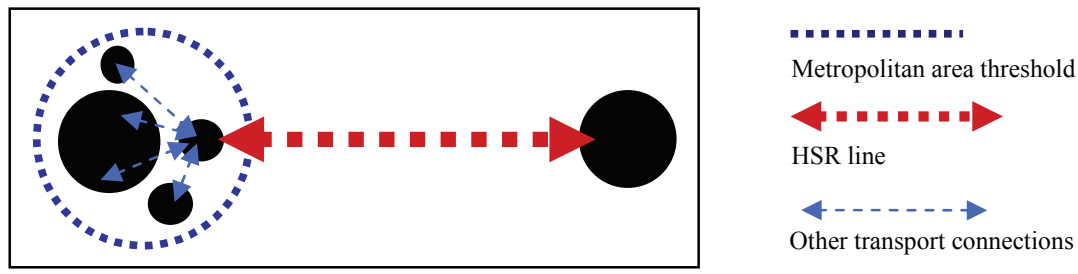

Figure 1: Small cities half an hour from a metropolitan area by HSR. Source: Ureña et al. [2].

In order that the HSR provides for these small cities to become metropolitan sub-centres, it is important for them to have tertiary activities and high-level services (Bonnafous [3]), a high-quality image, and that the HSR stations have an important number of services, be correctly located in the city and be connected with the metropolitan areas other transport networks (Garmendia [4]).

In any case, these HSR stations can also work as peripheral stations of the metropolitan area for the population living or working in the aforementioned periphery, avoiding transfers in the centre of the metropolitan area. The fact that this new type of HSR connection facilitates the integration of these small cities in the metropolitan corridor is foreseeable. Specifically, the factors that can determine the degree of this integration are the following:

- That previously to the HSR the small city was or was not located on a high-quality national transport corridor, it will strengthen the opportunities that already existed or it will create new possibilities (Ureña et al. [5]).

- Taking into account that the HSR usually transports people of a certain socio-professional level, the possibility that it opens new opportunities with the aforementioned cities will depend on the metropolitan corridor lodging population of qualified socio-professional groups and tertiary activities (Bonnafous [3], Ureña et al. [5] or Bellet [6]).

- The characteristics and the services of the city, that is, its environmental and urban quality, and the quality and diversity of its services. Being an administrative centre, having a university or a tertiary and dynamic economic base, will also improve the metropolitan integration capacity of the HSR (Garmendia et al. [7]).

- A central location of the station in the small city may facilitate the HSR to facilitate different opportunities (Troin [8]), either for its accessibility or for the projects that can happen in its surroundings. 
Besides, the way in which these small cities are engrafted in metropolitan and national corridors and the characteristics of the aforementioned corridors will have considerable effect on the opportunities generated by the HSR. At the present time, four alternatives of connection basically take place:

1. Cities with a pass-through HSR line that connects them with the metropolis: The small city has a station in the pass-through HSR line that connects it with the close metropolis and with other far away cities. This type of connection produces a reinforcement of the small cities as corridors that join the metropolitan area with other far away cities, allowing them to take part in the relations that take place at the aforementioned corridor. The HSR passing infrastructure at the same time enables the existence of rail services towards the close metropolitan area and towards the far away cities. Therefore, the HSR services along the infrastructure are the ones that can facilitate some relations and make other ones difficult, that is to say, the ones that determine the way these small cities articulate themselves in the corridor are services. Besides, the opportunities that the HSR can facilitate will depend, as we have already seen, on the position of the station in the small city (central or peripheral).

2. Cities with a "cul-de-sac" HSR line, connected exclusively with the metropolis: The small city has the HSR station in a "cul-de-sac" line that connects this city exclusively with the close metropolis.

This type of connection is the one that most looks like a metropolitan transportation system and least resembles the HSR conceived for long distances. In fact, this is an unusual case, and for the moment only one station with these characteristics, that of Toledo in Spain, is known, though there are similar cases, such as the one of Eskilstuna in Sweden, that we will also analyze, where the objective is connecting several small cities to the metropolis in a radius of little more of $100 \mathrm{~km}$.

3. Cities with a pass-through HSR line without connection with the close metropolis: The small city has a station in the HSR passing line that connects it with far away cities and lacks a HSR connection with the close metropolis.

This type of line does not connect with the centre of the metropolitan area, decentralizing the high-speed service to one point of this periphery that usually counts on a dense network of metropolitan and/or regional transportation. It is where more explicitly the metropolitan nature of these high-speed stations is understood and the most significant cases happen in the metropolitan area of Paris, specifically in Marne-laVallée, Roissy-Aéroport Charles de Gaulle and Massy.

4. Cities with several HSR lines passing-through the HSR station: The small city has a HSR passing line that connects it with the close metropolis and that bifurcates at the aforementioned city towards several far away cities or metropolises.

This type of connection is the one that opens up a larger number of opportunities for the small cities, favouring a reinforcement of their 
relations with several metropolitan areas. As infrastructures gain high capacity, an increase in the number of cities that undergo a strategic situation like this is foreseeable. In this work Tarragona's case, in Spain, is analyzed.

\section{Opportunities and challenges of peripheral HSR stations}

In order to put forward the opportunities of the HSR in the metropolitan integration of a small city when the station is located several kilometres from the city-centre (peripheral station), three cases are compared: Guadalajara and Segovia in Spain, and Macon in France.

Unlike Guadalajara and Macon, which were already situated along national high-speed corridors before the arrival of the HSR, in Segovia the new infrastructure implies a significant increase in its accessibility to Madrid, providing the first direct connection to the metropolis.

In addition to the traditional long-distance services, in Segovia the railway operator (RENFE) implements some specific HSR services between Segovia and Madrid, with best-suited schedules for labour relations and reduced fares. These services, non-existent in Guadalajara and Macon, allow the materialization of labour displacements with the centre of the metropolitan area along the HSR. Also, it is necessary to consider Segovia's historic and architectonic quality, which together with tertiary specific activities, such as tourism and a private university, may improve its metropolitan integration capacity.

Whereas in Guadalajara and Macon the peripheral location of the HSR station in relation to the city and to the other transportation facilities does not look like it will potentiate their metropolitan integration (Ribalaygua [9]), in the case of Segovia the fact is definitely foreseeable. In fact, only in this city is the establishment of an urban continuum to the station put forward as a primary objective (Fig. 2).
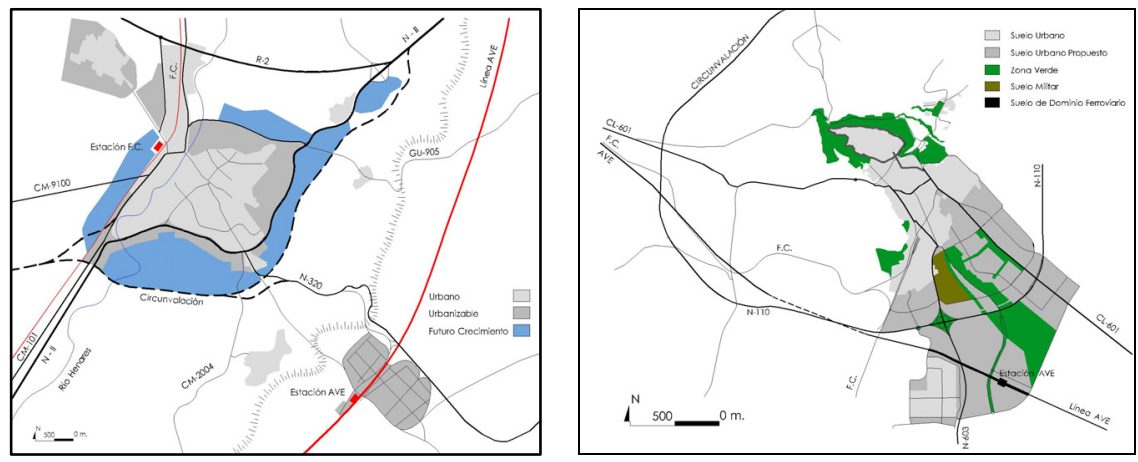

Figure 2: $\quad$ Future expansions of Guadalajara and Segovia cities. Source: Ribalaygua [10]). 
Regarding the role of the HSR station as a peripheral station for the metropolitan area, it is Guadalajara that gives rise to the most opportunities due to its proximity to the metropolitan centre $(60 \mathrm{~km})$ and its present integration in the metropolitan activities and space.

The HSR station at Tarragona, also peripheral, presents a singular interest in being where the Madrid-Barcelona and the future Barcelona-Valence lines will diverge. The complexity of HSR network in Tarragona consists of the attempt to locate the station in such a way that the three HSR itineraries (Madrid-Barcelona, Barcelona-Valence and Saragossa-Valence) may use lines from only one station.

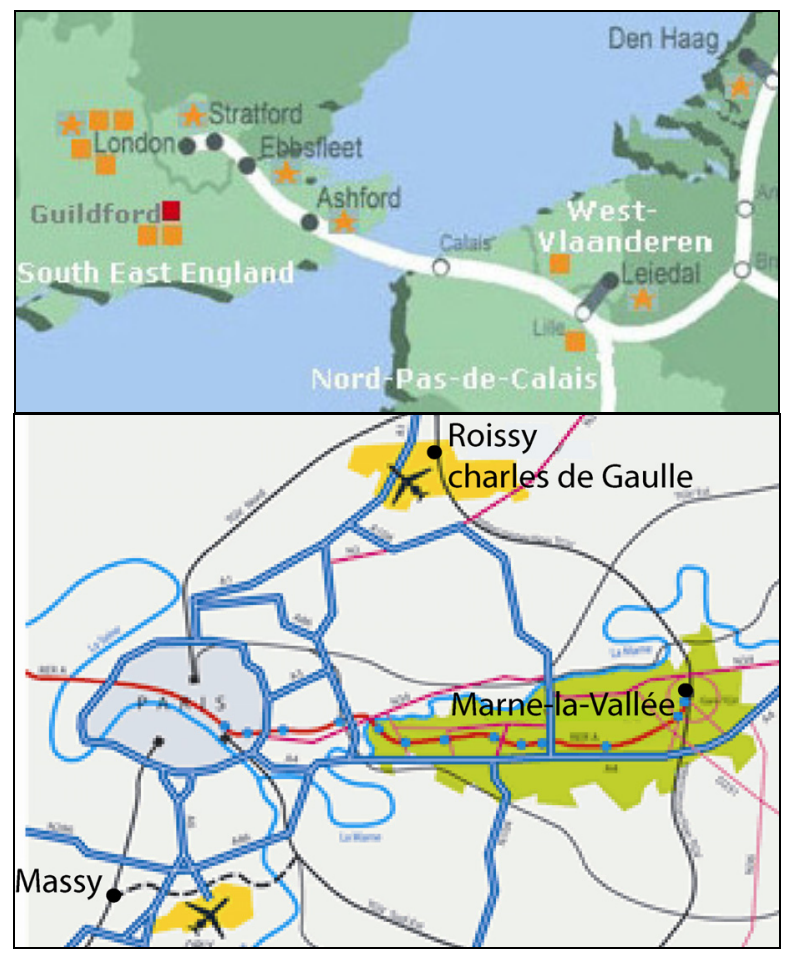

Figure 3: The HSR line in the southeast of England and HSR stations in the metropolitan area of Paris: Roissy - airport Charles de Gaulle, Marne-la-Vallée and Massy. Source: Self elaborate and EPAMARNE/EPAFRANCE.

\section{Metropolitan HSR services}

In London a new metropolitan HSR service is envisaged for 2009 that will connect London with three stations on the first $100 \mathrm{~km}$ of the HSR line: Stratford, Ebbsfleet and Ashford (Fig. 3). The establishment of these metropolitan services is possible because the freight traffic at the Channel Tunnel impedes the transit of Eurostars for significant periods of time. Besides, a 
great part of the HSR services between London and the continent will make a stop at Ebbsfleet's station (Jong [11]).

The regional metropolitan line between Stockholm and Eskilstuna, in Sweden, of $115 \mathrm{~km}$ length with four intermediate stations (which makes the travel time to cover the $115 \mathrm{~km} 1$ hour and five minutes), looks more like a metropolitan line than a traditional high-speed line. In this HSR line the number of travellers has been multiplied by seven since its velocity increase, and the percentage of the metropolitan journeys between the stations and Stockholm has increased from $6 \%$ to $30 \%$ (Fröidh [12]). This significant improvement in the railway service is probably favouring the population and real estate increase. However, there are no studies or opinions on the attraction capacity of tertiary activities, or on the possibility of becoming a sub-centre of the metropolitan area of Stockholm.

In Toledo the priority to maintain the traditional "cul-de-sac" railway station, because of its closeness to the historic centre, means the line lost the chance to become a pass-through line towards Andalusia and/or towards Lisbon. The location of the station, though near to the historic centre, turns out to be distant from the tertiary part of the city. This makes it difficult to bring about new tertiary high-level activities for this regional capital city that counts on a highquality image and university. Besides, given Toledo's proximity to Madrid (90 $\mathrm{km}$ ), it does not look like the HSR can substantially increment the number of tourists from the national capital city.

Finally, we can highlight the case of the metropolitan area of Paris, where the TGV line enables circumvallating of the centre of Paris for journeys between the northern and southern provinces. In these long-distance itineraries between provinces, there is no service to the capital, but rather to certain populations and services of the metropolitan area: Massy, Marne-la-Vallée and Roissy.

Marne-la-Vallée is a new linear city between 12 and $40 \mathrm{~km}$ east of Paris, which was projected in the late 1960s. This new city presents two singular spaces: Noisyle-Grand, the third centre of tertiary activities of the metropolitan area with international companies and several head offices; and the Cité Descartes, a centre of excellence in higher education and research, located at an intermediate position between Paris and Eurodisney. This environment has entrepreneurial and ludic characteristics fitted to be favoured for the HSR (useful for leisure or tourism concentrated shifts, such as Eurodisney) and it is very well connected to different long-distance transportation facilities (highways, HSR and airports).

The other two metropolitan HSR stations in Paris were also in two clearly metropolitan spaces before the HSR's arrival. The station of Massy, some $20 \mathrm{~km}$ south of Paris, is an ancient railway node where many traditional long-distance, suburban and HSR services stop. Roissy's station, at Charles de Gaulle airport, increases accessibility to the first French airport for the rest of the provinces.

\section{Travellers' profile in the new HSR metropolitan stations}

As we have seen, the utility of the HSR for the metropolitan dynamics depends on a lot of factors, such as the connection of the infrastructure within the city, the 
HSR services (frequency, tariff, schedules, etc.), the existence of alternative communications with the centre of the metropolitan area, and the very characteristics of the city.

Two surveys were carried out among the travellers of the HSR trains that stop at Guadalajara and Toledo in 2005 and 2008 respectively (Ribalaygua [13] and Rivas [14]). Important differences were found in the HSR travellers' profile and the employment of the infrastructures that are directly related to the existence (in Toledo) or not (in Guadalajara) of a specific short-distance HSR service with important frequencies, a reduced fare and a travel time to the centre of the metropolis environ of 30 minutes.

The percentage of commuters is found to be much greater in the relationship between Madrid-Toledo (44\%) than in the relationship between MadridGuadalajara (9\%). Whilst the labour or professional motive represents $41 \%$ in Toledo, it represents $27 \%$ in Guadalajara. The vicinity of Guadalajara to Madrid $(58 \mathrm{~km})$, greater than that of Toledo to Madrid $(89 \mathrm{~km})$, allows for labour shifts to the centre of the metropolitan area in different transportation means, such as the private car or the suburban railway. In Toledo, however, the specific metropolitan HSR service (11 trains/sense/day, a $9 €$ fare subject to season ticket and 30 minutes travel time), makes it possible to commute on the HSR. Besides, in Toledo, declared a World Heritage site by UNESCO, $36 \%$ of HSR journeys are motivated by tourist motives.

Guadalajara's vicinity to the centre of Madrid, along with the existence of an important network of communications of high capacity, makes the HSR station (besides peripheral) more useful for the population that lives in the periphery of Madrid and that wants to access outermost destinations, such as Saragossa or Barcelona, than for the population of Guadalajara wanting to access the centre of the metropolitan area. The survey shows that only $18 \%$ of HSR travellers that board or alight at Guadalajara have Madrid as their origin or destination, while the remaining $82 \%$ has far away cities for their origin or destination (at least $250 \mathrm{~km})$.

In Toledo, the infrastructural "cul-de-sac" lay-out prevents connections with faraway places, and therefore, the station's role is limited to one of a metropolitan transportation mode of better quality than the existent (dual carriageway and highway). In fact, $82 \%$ would have accomplished the journey had the HSR had not existed, and 43\% already accomplished the same shift before the HSR, in that case the private car being the principal transportation mode $(49 \%)$. Therefore, the new infrastructure upgrades a connection that existed previously, increasing the connection alternatives with the centre of the metropolitan area, but it does not prove to be determining in the choice of workplace (only $21 \%$ admits that the HSR has influenced the decision) or in the choice of residence (it has had influence only for $23 \%$ ). The suburban nature of this connection to Madrid is shown in the high percentage of commuters who live in Toledo and travel to work daily in Madrid. This unbalanced situation between those who live in Toledo and work in Madrid, and those who live in Madrid and work in Toledo ( $70 \%$ and $20 \%$ respectively) is much bigger than that found in other HSR lines, such as Ciudad Real-Madrid (Menéndez et al. [15]). 


\section{Conclusion}

We can talk, therefore, of a new mutation of the HSR into a high-speed metropolitan railway, halfway between the traditional HSR and the suburban traditional railways. It is indeed a special, complementary railway of the other traditional means of metropolitan transportation (roads, highways, suburban railways, subway, etc) that makes it possible to extend the metropolitan area to the threshold of 100 kilometres. There are two cases where this metropolitan HSR service is more like the suburban traditional railways, Ashford in London and Eskilstuna in Stockholm. Congestion and restrictions of access and parking in the centres of these two metropolises make such initiatives more reasonable.

The advantage of having two types of stations (central and peripheral) in big metropolitan areas had not been considered previously, rather on the contrary, it had been argued the advantage with HSR is that it could have central stations, contrarily to the airports. In some cases it has been proved that the connection of the HSR with the centre of the metropolis is not essential, but rather a good connection with the road, regional railway or metropolitan network (Ashford or Marne-la-Vallée and Massy, for example).

These HSR stations in the periphery of the metropolitan areas sometimes play the role of alternative stations to the central ones, most of all for the residents in the periphery of the aforementioned metropolitan areas and to a lesser extent for the economic activities that are set up at the aforementioned periphery.

In addition, it can be concluded that the outermost stations of the centre of the metropolitan area are not usually conceived for the aforementioned cities, though they sometimes arrive to facilitate their metropolitan integration (Segovia or Toledo in Spain). The chance for this metropolitan integration depends not only on the HSR infrastructure lay out among these small cities, but also on the rail services established at HSR stations.

\section{References}

[1] Plassard, F. TGV et aménagement du territoire. In Association Villes et TGV (ed.), Congress Villes et TGV at Le Creusot, October 1990, TEN, Paris, 1991.

[2] Ureña, J.M., Ribalaygua, C., Coronado, J.M. y Garmendia, M. Situaciones y retos territoriales de la Alta Velocidad Ferroviaria en España, Ciudad y Territorio. Estudios Territoriales, 148, pp. 397-424, 2006.

[3] Bonnafous, A. The regional impact of the TGV. Transportation 14, $127-$ 137, 1987.

[4] Garmendia, M. Cambios en la estructura urbana y territorial facilitados por la alta velocidad ferroviaria, la línea Madrid-Sevilla a su paso por la provincia de Ciudad Real, tesis doctoral de la Universidad de Castilla-La Mancha, 2008.

[5] Ureña, J.M., Menéndez, J. M., Guirao, B., Escobedo, F., Rodríguez, F. J., Coronado, J. M, Ribalaygua, C., Rivas, A. y Martínez, A. Alta Velocidad 
ferroviaria e integración metropolitana en España: el caso de Ciudad Real y Puertollano, EURE, Vol. XXXII, n. 92, pp. 87 - 104, 2005.

[6] Bellet, C. L'impacte de l'alta velocitat en ciutats intermèdies. El cas de ciudad Real. In Bellet, C. (ed.), Les oportunitats del Tren d'Alta Velocitat a Lleida, Pagès editors, Lleida, 2000.

[7] Garmendia, M., Ureña, J.M., Ribalaygua, C., Leal, J. y Coronado, J.M. Urban residential development in isolated small cities that are partially integrated in metropolitan areas by high speed train, European Urban and Regional Studies. Vol 15, n.3, pp. 265-280, 2008.

[8] Troin, J. F., Rail et aménagement du territoire. Des héritages aux nouveaus défis, Aix en Provence, Edisud, 1995.

[9] Ribalaygua, C. Alta velocidad y ciudad: estrategias de incorporación de las nuevas estaciones periféricas francesas y españolas. Colección Cuadernos de Investigación Urbanística, n 42, Instituto Juan de Herrera, Universidad Politécnica de Madrid, Madrid, 2005.

[10] Ribalaygua, C. Nuevas estaciones periféricas de alta velocidad ferroviaria: estrategias para su incorporación a las ciudades españolas Colección Cuadernos de Ingeniería y Territorio, n 5. Universidad de Castilla- La Mancha, Ciudad Real, 2005.

[11] Jong, M. Attractiveness of HST Locations, Eight Cases in Northwest Europe, Master Thesis en Urban Planning en la Universidad de Amsterdam, 2007.

[12] Fröidh, O. Market effects of regional high-speed trains on the Svealand line, Journal of Transport Geography, Vol. 13, n. 4, pp. 352-361, 2005.

[13] Ribalaygua, C., Sánchez, J.J., Coronado, J.M., Garmendia, M. y Ureña, J.M. Línea de alta velocidad Madrid-Barcelona: primeros estudios y reflexiones sobre las ciudades intermedias. VII Congreso de Ingeniería del Transporte, Ciudad Real, 14-17 Junio. (ISBN - 84-689-8341-1), 2006.

[14] Rivas, A. Análisis de ciudades de tamaño medio próximas a una metrópolis, El servicio de alta velocidad ferroviaria entre Madrid y Toledo. Efectos sobre la movilidad. III Jornada sobre Alta Velocidad y Territorio, Ciudad Real, 2008.

[15] Menéndez, J. M., Coronado, J. M. y Rivas, A. La AVF en Ciudad Real y Puertollano: Notas sobre su incidencia en la movilidad y el territorio. Ed. E.T.S.I. Caminos, Canales y Puertos, UCLM, colección Cuadernos de Ingeniería y Territorio, n. 2, 2002. 